\title{
The Strategies to Increase Customer Value in Agile: A Survey of Brazilian Software Industry
}

\author{
Fernando Sambinelli ${ }^{1 *}$, Marcos Augusto Francisco Borges ${ }^{1}$ \\ 1 School of Technology, University of Campinas (UNICAMP), BRAZIL
}

*Corresponding Author: f180172@g.unicamp.br

Citation: Sambinelli, F. and Borges, M. A. F. (2019). The Strategies to Increase Customer Value in Agile: A Survey of Brazilian Software Industry. Journal of Information Systems Engineering \& Management, 4(2), em0090. https://doi.org/10.29333/jisem/5889

Published: August 22, 2019

\begin{abstract}
Previous empirical studies have demonstrated the relevance of the concept of customer value to the software industry and the state-of-the-art of strategies to increase customer value in Agile Software Development (ASD) has been recently documented in a Systematic Literature Review (SLR). However, to date, there are no studies on the state of practice for this area focusing on issues similar to those investigated in the SLRs mentioned above. The objective of this article was to report on the state of the practice of adopting strategies to increase customer value in the ASD and to detail these strategies concerning goals pursued, customer value metrics, challenges and usage impacts, and the reasons for non-adoption. A survey was performed using a web questionnaire answered by software professionals who are members of agile teams. Data were collected from 378 respondents from 123 Brazilian software intensive organizations. Prioritizing the development of high-value customer features and validating them frequently $(92.3 \%)$, as well as focusing on value aspects of the client's market segment and applying the most relevant agile practices to make them viable $(64.8 \%)$, appeared to be the strategies most frequently practiced by agile teams. Generally, the experiences of using these strategies appear to be very positive, although challenges have also been identified, such as defining what customer value and customer collaboration is.
\end{abstract}

Keywords: agile, customer value, product development

\section{INTRODUCTION}

One of the critical characteristic of Agile Software Development (ASD) is its explicit focus on customer value (Conboy, 2009). In the first principle of the Agile Manifesto (Beck et al., 2001), it is possible to observe the priority given to customer satisfaction through early and continuous delivery of valuable software. Similarly, the principles of Lean Thinking, an original approach to Toyota that influenced ASD, point to the need to increase customer value by eliminating wasteful activities or processes that do not generate value (Poppendieck, 2011).

The concept of customer value takes into account the perspective of a company's customers, whether internal or external, considering what they want and believe by the purchase or use of a product or service (Khalifa, 2004). However, this concept is referred to in the literature as complex, difficult to understand, conceptualize and model (Andreu et al., 2010). It has different meanings in specific contexts and is continuously influenced by new experiences and customer needs (Salleh et al., 2010). In agile development, most decisions should be made by customer value (Khurum et al., 2013). However, it is challenging to estimate and calculate the value of the software (Racheva, Daneva, Sikkel and Buglione, 2010; Sambinelli and Borges, 2019a). It is not merely a matter of the absence of defects. It is possible to deliver software without defects, but with little or no value for the client (Gilb, 2017). 
The primary goal of any business organization is to create, deliver, and maintain a flow of value to its customers in a sustainable and growing manner. Customer value has been the focus and need of companies worldwide (Mohammed et al., 2008), including the software industry (Boehm, 2006). The domain of customer value is a crucial element for the success of companies (Barney et al., 2008; Komssi et al., 2015). However, challenges of the practical application of strategies to increase customer value are still present in software development with products of low value and underutilized (Forrester, 2013; Pass and Ronen, 2014). Development teams today are often functional factories, failing to assess whether delivered product functions solve customer's problems (Cagan, 2018). Despite the clear priority in the Agile Manifesto, the various agile approaches do not include any specific ceremony to track value delivery results, allowing each team to choose whether or not to adopt strategies to achieve that goal. Moreover, the metrics adopted by agile teams to measure the effectiveness of software deliveries in delivering the expected value by customers are rare (Alahyari et al., 2017). In software engineering surveys, few studies have been devoted to understanding the concept of customer value in a broad and detailed way (Alahyari et al., 2017). Particularly in the ASD, few empirical studies investigate the means used by agile teams to increase customer value in development processes and projects (Kasauli et al., 2017).

This article reports results from an exploratory survey conducted in 2018 with 378 participants. Its objective was to discover, analyze and present empirical results related to the adoption of strategies to increase customer value in Brazilian software-intensive organizations that use agile methods. The study addressed the following research questions: (RQ1) What is the current situation of adopting strategies to increase customer value? (RQ2) What are the objectives by which strategies to increase customer value are being adopted? (RQ3) What are the impacts, regarding benefits or side effects, of using strategies to increase customer value? (RQ4) What are the critical factors that may challenge the use of strategies to increase customer value? (RQ5) What are the reasons why some organizations do not use strategies to increase customer value?

This paper makes the following contributions to research and practice: I) it provides more up-to-date results on the state of practice of strategies to increase customer value in the ASD using first-hand industrial data. Other organizations can harness the results through a better understanding of the strategies that their peers are using, the main objectives to adopt them, as well as their benefits and challenges; II) it presents the first large-scale exploratory study analyzing the state of the practice on strategies to increase the value for the client in agile software development; III) the results of this study provide the basis for future research, identifying the most commonly used customer value strategies and metrics, as well as the most frequently obtained benefits and usage challenges. These elements may guide the research agenda of other initiatives, such as case studies or experiments, which study in more depth the specific benefits and challenges that agile organizations face when implementing strategies to increase customer value.

The remainder of the paper is organized into four sections. The first one reviews previous studies on strategies to increase customer value in agile development. Next, the Research Setting section describes the research settings, including the data collection process and the survey design. The Results section includes a systematic and comprehensive presentation of survey questions and research results. In the end, the last section concludes the paper by summarizing the results and presenting the limitations of the study.

\section{RELATED WORK}

Value-Based Software Engineering (VBSE) has been proposed as a value-related approach for the customer (Komssi et al., 2015). The VBSE recommends that financial value perspectives be integrated into software engineering processes to extend their reach on technical issues to achieve business-relevant aspects (Biffl et al., 2006). However, several studies have pointed out that, although the VBSE has contributed significantly to the evolution of the understanding of customer value creation in software development, it does not explicitly define the concept of value for the client or the strategies that increase value (Murtazaev et al., 2010; Ramzan et al., 2009), focusing only on financial aspects.

The literature related to customer value in the ASD still has few studies (Alahyari et al., 2017). Although most of the published works do not specifically analyze the strategies adopted to increase customer value, some of them have been published recognizing value creation through agile practices (Conboy, 2009; Racheva, Daneva, Sikkel and Buglione, 2010; Santos et al., 2011). Other researchers presented theoretical constructs of value necessary for making decisions about the development of software products. However, contributions are often isolated and with limited focus, such as quality only (Conboy, 2009; Santos et al., 2011), usability and simplicity (Conboy, 2009; Maruping et al., 2009), frequent releases (Hoda et al., 2011; Kasauli et al., 2017) or the financial aspect (Conboy, 2009; Kim et al., 2007).

In order to better understand how agile teams interpret and act on the value in projects, a systematic review study concluded that publications only cite value creation through agile methods, but do not present empirical evidence (Racheva, Daneva, Sikkel and Buglione, 2010). The authors of this paper did not find some individual or 
some organization that indicated how agile practices or groups of practices create value for the client. The need to conduct empirical research on value creation in agile projects was mentioned as one of its implications.

While customer value and its role as input for prioritizing and planning releases in agile projects have been critically discussed (Cleland-Huang, 2015; Golfarelli et al., 2013; Racheva, Daneva, Sikkel, Herrmann, et al., 2010), other researchers (Alahyari et al., 2017) have begun to investigate this gap, i.e., how the value is interpreted, prioritized, guaranteed and measured in agile software development. They identified and prioritized aspects of value such as the delivery process (concerning time), the quality and the knowledge of the value of each feature to the client. The authors also found empirical evidence that there are different perceptions of value for different market segments. They suspect that the types of products developed can explain the differences. They also indicate which practices are most commonly used to achieve higher customer value and what prevents them from achieving that value. The study, however, limited the scope of strategies to increase customer value for traditional agile practices, which restricted the results to a limited set of practices.

Based on extensive theoretical work on customer value models (Khalifa, 2004), an SLR study (Sambinelli and Borges, 2019b) identified 15 strategies to increase customer value in agile development based on academic studies and experience reports of the industry. The research has taken broad perspectives from the literature on Management and Marketing that group customer value models into three main groups: value components models, benefit-cost ratio models, and means-end models. Strategies were identified and detailed at the level of approaches, techniques, tools, and metrics. The results obtained reinforced the complexity and the need for new empirical studies on the subject, mainly to investigate the critical success factors and the main challenges for the adoption of these strategies, as well as the impacts caused by their implementations in practice. The implications of this systematic review have motivated the research described in this paper.

\section{RESEARCH SETTING}

In this section, the research settings are presented, describing data collection, survey design, and mitigation strategies to validity threats of the study.

\section{Data Collection}

The target population of the survey was software professionals, members of agile teams, who worked in companies in Brazil. Data collection was conducted between November and December 2018, using the SurveyMonkey web questionnaire tool. Five experts in agile development previously reviewed the questionnaire and six software professionals pre-tested it to verify their consistency and legibility. Following an accidental sampling approach (Fowler, 2013), potential respondents were invited directly by email and postings on agile development-related mailing lists. Many of them were contacted through a group using the Slack tool (http://agilidade.slack.com) and the professional network Linkedin. A snowball sampling approach (Fowler, 2013) was also used through the contacts of the responsible researchers. An estimated 6,700 people were contacted, and 378 answers $(5.6 \%)$ were obtained. These professionals represented 123 different organizations, distributed along 18 Brazilian states. These responses were filtered and contained only respondents who reported using agile methods. The general profile of respondents is presented in Section IV.

\section{Survey Design}

The survey design was based on a guide for conducting surveys in software engineering (Linaker et al., 2015). The objective was to describe the extent of adopting strategies to increase customer value in the participating software professional's team, as well as explore the reasons and effects of adoption. The survey, including twentyseven questions, was elaborated based on the literature on customer value in the ASD, particularly in the SLR by Sambinelli and Borges (Sambinelli and Borges, 2019b). Survey questions were organized in two parts: Part 1 collected demographic data, while Part 2 collected data on respondents' practical experience in strategies to increase customer value in agile teams. The questions in Part 2 were intended to answer the research questions described in Section I and were organized into three groups:

- Use of strategies to increase customer value consisted in the following issues: adoption of strategies by the participant team; use of specific strategies to increase customer value and adoption of customer value metrics;

- Objectives, challenges, and impacts on adoption consisted of the following issues: objectives expected by the adoption of strategies to increase customer value; challenges encountered in seeking to increase customer value; impacts observed when adopting strategies to increase customer value;

- Reasons for the non-adopter were formed by a single question that listed possible reasons for non-adoption of strategies to increase customer value. 
Table 1. Positions in Organization

\begin{tabular}{lclc}
\hline Position & n & Position & n \\
\hline Agile Coach/Consultant & 20 & Product Owner & 32 \\
\hline Business Analyst/Requirements & 9 & Project Manager/Program & 40 \\
\hline Developer & 105 & Scrum Master & 40 \\
\hline Executive/Director & 14 & Technical Leader/Architect & 66 \\
\hline Infrastructure & 3 & Tester & 22 \\
\hline Intern & 5 & Other & 22 \\
\hline
\end{tabular}

Although preliminary options for answers were presented in the questions in part 2 of the survey, the questionnaire included open fields to indicate other options not considered in the preliminary list and also the "do not know" option.

\section{Threats to Validity}

The four types of threats to the validity of the results, suggested by Yin (2017), were identified and the corresponding mitigation strategies were applied:

- Construct validity is related to problems that may arise due to the inadequate design of the survey instrument, which may not be adequately measuring what it should measure. It is considered that this question has been attenuated since the questionnaire was designed interactively and updated by the authors based on the results of a systematic literature review (Sambinelli and Borges, 2019b). Also, five experts on agile methods validated the questionnaire regarding their completeness and readability, and six other professionals participated in a pretest by reporting feedback;

- Internal validity is concerned with issues such as confounding factors or irrelevant respondents that could introduce a systematic error or bias in the study results. Two measures were taken to mitigate this threat: (I) Respondents were asked about their experience with agile methods to ensure that all respondents were agile practitioners. Respondents who did not have experience in agile methods were disqualified from the survey; (II) The anonymity of the participants was ensured to avoid apprehension of evaluation;

- External validity refers to the extent to which the findings in a study are applicable outside the context of the study. As the sample used in this study was an accidental sample, the results are only generalizable for agile teams and companies that share characteristics similar to teams and companies of survey participants. However, some actions such as advertising this survey in forums and online groups related to agile methods as well as a snowball approach have been taken to get a broad cross-section of the target population. It is believed that these actions contributed to obtaining a sample that is quite heterogeneous regarding experience, position, and company size;

- Reliability refers to the effects on the results when the researchers perform data collection and analysis (Yin, 2017). In this study, we used only frequencies and percentages to explore strategies to maximize customer value or potential relationships for future research efforts. Besides, we considered only complete responses for analysis. Incomplete responses were not subjected to any subsequent follow-up to increase the response rate.

\section{RESULTS}

This section presents the results of the survey organized according to the research questions, preceded by demographic data that aimed to understand the context and the background of the respondents.

\section{Demographics of Respondents}

The number of respondents to the survey was 378. Respondents were working in various positions within their organizations. The main organizational roles of respondents were developers $(n=105)$ and technical leaders / software architects $(n=66)$. Another profile data of the respondents is that almost $50 \%$ had more than ten years of experience in software development. Table 1 presents the respondents' positions in their organizations.

The respondents belonged to 123 different organizations, distributed in 18 Brazilian states. Some of the participants did not identify their organizations $(n=3)$. Most organizations were large $(58.0 \%$, 500 or more employees) and medium-sized (28.3\%, number of employees between 100 and 499$)$. Small and micro-enterprises, with 99 or fewer employees, accounted for $13.7 \%$ of representation in the data.

Table 2 shows information on agile methods' experience of respondents and their organizations, along with corresponding frequencies and percentages. Almost $40 \%$ of the respondents had five years or more of experience while almost 7\% worked with agile methods for less than one year. Respondents were also asked to provide information about their organizations' total experience with agile methods. Most organizations, totaling $40.2 \%$ (n 
Table 2. Experience in Agile Methods

\begin{tabular}{|c|c|c|c|c|}
\hline \multirow{2}{*}{ Work Experience } & \multicolumn{2}{|c|}{ Participants } & \multicolumn{2}{|c|}{ Organization } \\
\hline & $\mathbf{n}$ & $\%$ & $\mathrm{n}$ & $\%$ \\
\hline Less than 1 year & 26 & 6.9 & 19 & 5.0 \\
\hline $1-2$ years & 52 & 13.7 & 47 & 12.4 \\
\hline $2-5$ years & 145 & 38.4 & 116 & 30.7 \\
\hline 5 years or more & 150 & 39.7 & 152 & 40.2 \\
\hline Unknown & 5 & 1.3 & 44 & 11.7 \\
\hline Total & 378 & 100.0 & 378 & 100.0 \\
\hline
\end{tabular}

Table 3. Product Owner Profile in the Agile Team

\begin{tabular}{lcc}
\hline Product Owner Profile & $\mathbf{n}$ & $\mathbf{\%}$ \\
\hline Employed by the organization of the participant & 186 & 49.9 \\
\hline Client representative & 153 & 41.0 \\
\hline No product owner & 7 & 1.9 \\
\hline Other & 24 & 6.4 \\
\hline Unknown & 3 & 0.8 \\
\hline Total & 373 & 100.0 \\
\hline
\end{tabular}

Table 4. Product Owner Profile in the Agile Team

\begin{tabular}{lcc}
\hline Product Owner Profile & $\mathbf{n}$ & $\mathbf{\%}$ \\
\hline Employed by the organization of the participant & 186 & 49.9 \\
\hline Client representative & 153 & 41.0 \\
\hline No product owner & 7 & 1.9 \\
\hline Other & 24 & 6.4 \\
\hline Unknown & 3 & 0.8 \\
\hline Total & 373 & 100.0 \\
\hline
\end{tabular}

=152), have adopted agile methodologies in their software development processes for five years or more. For $11.7 \%(\mathrm{n}=44)$ of the participants, the organization's experience with agile methods was not known to them.

Most respondents reported that their teams specifically implemented the Scrum method $(43.4 \%, \mathrm{n}=162)$. The second and third most adopted methods among the teams were, respectively, Kanban $(17.4 \%, \mathrm{n}=65)$ and hybrid methods $(13.4 \%, \mathrm{n}=50)$.

About $50 \%$ of the product owners who worked in respondent agile teams were employees of their organization, while $41 \%$ were representatives of the client organization. Less than $2 \%$ of respondents indicated that no product owner working with their team. The profiles of the product owners of respondents' teams are presented in Table 3.

Agile respondent teams were working for different customer profiles and market segments. Almost $60 \%$ of respondents 'typical clients were external organizations, while developments for areas and departments internal to the participants' organization totaled just over 13\%. The provision of outsourced services, when the software developed aims to serve the customers of the organization that hires the participant's team, totaled almost $21 \%$. Only 5.1\% ( $\mathrm{n}=19)$ of respondents indicated the option "Other" in their clients' profile and less than one percent did not know how to respond. To complement the profile of the clients of agile teams of respondents, in Table 4 it is possible to observe the distribution of their respective market segments. Participants were able to choose more than one answer option.

\section{RQ1: Adoption of Strategies to Increase Customer Value}

In one of the survey questions, respondents were reminded of the first principle of the Agile Manifesto that points to the need to satisfy the customer through early and continuous delivery of valuable software. Three examples of strategies to increase customer value found in the literature were cited (Sambinelli and Borges, 2019b). Following, they were asked if the respondent's team had any strategy to achieve this goal. About $89 \%$ of respondents said that they adopted strategies to maximize customer value, while only $9 \%(\mathrm{n}=35)$ indicated they did not. Less than $2 \%(n=6)$ did not know how to respond.

Respondents indicated the strategies that have been adopted by their agile teams to increase customer value. The list of strategy options was based on SLR by Sambinelli and Borges (Sambinelli and Borges, 2019b). Table 5 presents, in increasing frequency order, the strategies adopted by respondent teams to increase customer value.

Two strategies indicated on SLR (Sambinelli and Borges, 2019b), which dealt with the prioritization of features by higher customer value, were unified in a single strategy due to the close conceptual similarity. The resulting 14 strategies were grouped in random order into a single survey question. Participants could select more than one strategy in use by their team, respond that they did not adopt any or indicate they did not know. For more than $92 \%$ of respondents, the most commonly used strategy is to prioritize the development of higher value customer features and to validate them frequently (E1). Less than $1 \%$ did not know how to respond. 
Table 5. Strategies for increasing Customer Value

\begin{tabular}{|c|c|c|}
\hline Strategy & $\mathrm{n}$ & $\%$ \\
\hline $\begin{array}{l}\text { E1: Prioritize the development of higher value customer features and validate them } \\
\text { frequently }\end{array}$ & 312 & 92.3 \\
\hline $\begin{array}{l}\text { E2: Focus on aspects of value (such as quality, usability, and on-time delivery) more priority } \\
\text { for the client's market segment and apply the most relevant agile practices to enable them }\end{array}$ & 219 & 64.8 \\
\hline $\begin{array}{l}\text { E3: Seek to increase customer satisfaction through the union of an organizational culture of } \\
\text { process agility and maturity }\end{array}$ & 202 & 59.8 \\
\hline E4: Improving the predictability and productivity of software development & 193 & 57.1 \\
\hline $\begin{array}{l}\text { E5: Improve the efficiency of software development project management (deadline, cost, } \\
\text { and scope) }\end{array}$ & 183 & 54.1 \\
\hline E6: Increase the motivation of development team members and organizational learning & 181 & 53.6 \\
\hline $\begin{array}{l}\text { E7: Apply continuous cycles of experimentation and learning to find out what customers } \\
\text { want }\end{array}$ & 179 & 53.0 \\
\hline E8: Synchronize teams and optimize the product to reduce cycle time to customer & 170 & 50.3 \\
\hline $\begin{array}{l}\text { E9: Increase the functional and non-functional quality of the product, without neglecting the } \\
\text { management of the invested resources }\end{array}$ & 155 & 45.9 \\
\hline $\begin{array}{l}\text { E10: Plan roadmapping based on a deep understanding of customer needs and a long-term } \\
\text { view }\end{array}$ & 148 & 43.8 \\
\hline E11: Increase strategic alignment of all software development projects of the company & 148 & 43.8 \\
\hline $\begin{array}{l}\text { E12: Maximizing the "cost } x \text { benefit" ratio by quantifying benefits, not just costs, and } \\
\text { improving cost management efficiency }\end{array}$ & 124 & 36.7 \\
\hline $\begin{array}{l}\text { E13: Increase the visibility of software quality to customers through the dissemination of } \\
\text { measurements during the development phase }\end{array}$ & 124 & 36.7 \\
\hline $\begin{array}{l}\text { E14: Consider the value created for customers through software products developed as a } \\
\text { criterion in evaluations of employees' organizational performance }\end{array}$ & 92 & 27.2 \\
\hline Others & 21 & 2.3 \\
\hline
\end{tabular}

Table 6. Metrics of Customer Value

\begin{tabular}{llc}
\hline Metrics & $\mathbf{n}$ & $\mathbf{\%}$ \\
\hline Number of defects per period & 174 & 51.5 \\
\hline Amount of work in progress & 154 & 45.6 \\
\hline Cycle time & 152 & 45.0 \\
\hline Benefit points or business value points & 124 & 36.7 \\
\hline Metrics based on consumer feedback during product use & 123 & 36.4 \\
\hline Customer experience or satisfaction metrics (such as net promoter score, churn rate, & 118 & 34.9 \\
\hline customer satisfaction score) & 114 & 33.7 \\
\hline \% of the estimated scope of the product to be delivered within & 111 & 32.8 \\
\hline Points for user history & 109 & 32.2 \\
\hline Cost (financial) & 84 & 24.9 \\
\hline Productivity of the benefit points or points of value & 83 & 24.6 \\
\hline Return on Investment & 79 & 23.4 \\
\hline Successful design metrics based on customer value & 74 & 21.9 \\
\hline Average time to stabilize a software version available to the customer & 41 & 12.1 \\
\hline Benefit or cost performance index & 34 & 10.1 \\
\hline Function points & 34 & 10.1 \\
\hline Operating expenses by a period & 27 & 8.0 \\
\hline Total dependencies for functionality & 9 & 2.7 \\
\hline Other & & \\
\hline
\end{tabular}

Respondents were asked to indicate the metrics used by their teams to measure customer value. The majority reported that their teams, specifically, adopted the metric of the number of defects per period $(51.5 \%, \mathrm{n}=174)$. The second and third metrics most used among them were, respectively, the amount of work in progress $(45.6 \%$, $\mathrm{n}=154)$ and the cycle time $(45.0 \%, \mathrm{n}=152)$. Less than $4 \%$ of respondents indicated that they did not use any metric of value to the client. Only 1.8\% $(\mathrm{n}=6)$ did not know how to respond. Participants were able to choose more than one answer option. The list of customer value metrics reported by attendees is listed in Table 6 .

\section{RQ2: Goals Sought in the Adoption of Strategies}

Respondents were also asked to identify the goals of their agile teams in adopting strategies to increase customer value. Participants were able to choose more than one answer option. For almost $90 \%$ of the participants' teams, increasing customer satisfaction is the main reason for adopting a strategy, followed by a quest to increase customer loyalty, which accounts for approximately $67 \%$ of respondents. Less than $2 \%$ did not know how to respond. The objectives of the adoption of the strategies are presented in Table 7 together with the corresponding frequencies and percentages. 
Table 7. Goals in the Adoption of Strategies

\begin{tabular}{lcc}
\hline Goals & $\mathbf{n}$ & $\mathbf{\%}$ \\
\hline Increase customer satisfaction & 304 & 89.9 \\
\hline Increase customer loyalty (retention) & 226 & 66.9 \\
\hline Promoting a culture of innovation and learning in the company that develops the product & 197 & 58.3 \\
\hline Improve the software development process & 193 & 57.1 \\
\hline Increase the competitive advantage of the company that develops the product & 187 & 55.3 \\
\hline Increase the chances of success of the company that develops the product & 186 & 55.0 \\
\hline Increase profits from the developed product & 164 & 48.5 \\
\hline $\begin{array}{l}\text { Increase the satisfaction of the stakeholders of the company that develops the product (e.g. } \\
\text { shareholders, employees, etc.) }\end{array}$ & 161 & 47.6 \\
\hline Reduce risk & 123 & 36.4 \\
\hline Others & 2 & 0.6 \\
\hline
\end{tabular}

Table 8. Impacts of the Adoption of Strategies

\begin{tabular}{lcc}
\hline Impacts & $\mathbf{n}$ & $\mathbf{\%}$ \\
\hline Improvement in communication & 211 & 62.4 \\
\hline Improved customer satisfaction & 207 & 61.2 \\
\hline Improved customer collaboration & 190 & 56.2 \\
\hline Improved ability to adapt to change & 189 & 55.9 \\
\hline Improvement in the quality of the development process & 188 & 55.6 \\
\hline Improved productivity & 177 & 52.4 \\
\hline Improved software quality & 171 & 50.6 \\
\hline Improved customer understanding & 170 & 50.3 \\
\hline Improvement in learning and knowledge creation & 140 & 41.4 \\
\hline Reduction of waste & 131 & 38.8 \\
\hline Time-to-market acceleration & 119 & 35.2 \\
\hline Reduction of cycle time & 119 & 35.2 \\
\hline Reducing risks & 109 & 32.2 \\
\hline Increase sales / new business & 70 & 20.7 \\
\hline Reduction of costs & 52 & 15.4 \\
\hline Others & 6 & 1.8 \\
\hline
\end{tabular}

Table 9. Challenges in Adopting Strategies

\begin{tabular}{lcc}
\hline Challenges & $\mathbf{n}$ & $\mathbf{0}$ \\
\hline Define what is customer value & 208 & 61.5 \\
\hline Customer collaboration & 158 & 46.8 \\
\hline Maturity of the team in agile methods & 119 & 35.2 \\
\hline Synchronization between multiple partners & 112 & 33.1 \\
\hline Learning curve & 92 & 27.2 \\
\hline Resistance to change by the team & 80 & 23.7 \\
\hline Management commitment & 78 & 23.1 \\
\hline Need for competence and specialized skills & 69 & 20.4 \\
\hline Reducing predictability & 69 & 20.4 \\
\hline Team contracting model & 58 & 17.2 \\
\hline Inadequate training & 51 & 15.1 \\
\hline Lack of formal guides and documentation & 50 & 14.8 \\
\hline Inadequate existing tools and techniques & 34 & 10.1 \\
\hline Increased development cost & 33 & 9.8 \\
\hline Others & 2 & 0.6 \\
\hline
\end{tabular}

\section{RQ3: Impacts of the Adoption of Strategies}

Through this research question, we sought to understand how the adoption of strategies to increase customer value has affected the agile teams of the respondents. Participants were able to choose more than one answer option. More than $62 \%$ of the professionals described an improvement in communication after using some strategy, and around 61\% reported an improvement in their clients' satisfaction. Less than 2\% did not know how to respond. The list of impacts reported by respondents is presented in Table 8.

\section{RQ4: Challenges of the adoption of Strategies}

Participants were asked to report the main difficulties encountered by their agile team in seeking to increase customer value through some strategy for that purpose. In Table 9 it is possible to observe the main challenges indicated by the participants.

Most of the respondents (more than 61\%) pointed out that defining what is customer value is the biggest challenge of their teams. Almost $47 \%$ of the participating agile team members indicated the difficulty of 
Table 10. Reasons for Non-adoption of Strategies

\begin{tabular}{lcc}
\hline Reasons & $\mathbf{n}$ & $\mathbf{\%}$ \\
\hline Immaturity of the client to adopt the strategies & 20 & 57.1 \\
\hline Very traditional organizational culture & 19 & 54.3 \\
\hline Instability of software requirements & 12 & 34.3 \\
\hline Lack of knowledge or training & 11 & 31.4 \\
\hline Lack of managerial support & 10 & 28.6 \\
\hline Resistance to changes by the team & 8 & 22.9 \\
\hline Team contracting model & 7 & 20.0 \\
\hline Inappropriate existing techniques or tools & 6 & 17.1 \\
\hline Increased development cost & 4 & 11.4 \\
\hline Customer market segment strength & 3 & 8.6 \\
\hline Reduced predictability & 3 & 8.6 \\
\hline Others & 6 & 17.1 \\
\hline Unknown & 2 & 5.7 \\
\hline
\end{tabular}

collaborating with the client in implementing the strategies as a relevant barrier to be overcome. Less than $2 \%$ did not know how to respond.

\section{RQ5: Reasons for Non-adoption of Strategies}

Survey responses showed that 35 professionals indicated that in their agile teams they were not using any strategy to increase customer value. Non-adopters were asked questions about the reasons why they, or their teams, did not consider such strategies appropriate for their software development activities. The results of these reasons are presented in Table 10.

The results of Table 10 show that the most commonly reported reasons for impeding strategies to increase customer value are client immaturity and organizational culture very traditional in participant organization.

\section{LIMITATIONS OF THE STUDY}

This study presents some limitations that must be taken into account when interpreting its results. The study participants were professionals from different organizations. Although it would be more appropriate to use organizations as sampling units to consider the adoption of strategies to increase customer value more accurately at the organizational level, it is necessary to consider that companies can be formed by teams that implement different strategies with this goal. Therefore, it is reasonable to assert that it is inappropriate for a single person to respond to the whole organization. Therefore, this work focused on the contribution of the participants to the context of their work teams. Associated with this question, the respondent professionals were acting in different positions and functions in the companies. People in different organizational positions may have different views of organizational practices, as well as different insights into strategies to increase customer value, which can affect the reliability of results to some degree. To mitigate this and other possible threats to the validity of the study, a set of actions were taken in the configuration of the research, which was described in Section III. Despite its limitations, the study can provide valuable descriptive information on the current status of adoption of strategies to maximize customer value in agile software development organizations.

\section{CONCLUSIONS}

The results indicated that around $89 \%$ of the agile teams represented in this study had implemented strategies to maximize customer value. The two most commonly adopted strategies are: (I) to prioritize the development of higher value features for the client and to validate them frequently (92.3\%); and (II) to focus on the most important aspects of value for the client's market segment and to apply the most relevant agile practices to make them viable $(64.8 \%)$. Although some customer value metrics have been identified in the recent literature [30], the number of defects per period is still the most practiced measure to quantify customer value (51.5\%), followed by the amount of work in progress $(45.6 \%)$. This can be interpreted as indicative of the lack of maturity of software companies to assess the real delivery of value to the customer - as already reported by other researchers (Kasauli et al., 2017; Racheva, Daneva, Sikkel and Buglione, 2010), since both metrics are intended to relate aspects of elementary quality of the product and the software production process and little explanation about the value perceived by the customers. Increasing customer satisfaction and increasing customer loyalty (retention) has been reported as the primary goals for adopting strategies aimed at increasing customer value. About benefits and challenges, improved communication and customer satisfaction were indicated as significant benefits of using strategies to increase customer value. The difficulty in defining what is value for the client and the obstacles to obtaining its collaboration 
during software development seem to be the main challenges for organizations to adopt these strategies. Finally, the most common reasons to avoid adopting strategies to increase customer value are customer immaturity by adopting strategies and a very traditional organizational culture.

\section{REFERENCES}

Alahyari, H., Berntsson Svensson, R. and Gorschek, T. (2017). A study of value in agile software development organizations. Journal of Systems and Software, 125, 271-288. https://doi.org/10.1016/j.jss.2016.12.007

Andreu, L., Sánchez, I. and Mele, C. (2010). Value co-creation among retailers and consumers: new insights into the furniture market. Journal of Retailing and Consumer Services, 17(4), $241-250$. https:// doi.org/10.1016/j.jretconser.2010.02.001

Barney, S., Aurum, A. and Wohlin, C. (2008). A product management challenge: creating software product value through requirements selection. Journal of Systems Architecture, 54(6), 576-593. https:/ / doi.org/10.1016/j.sysarc.2007.12.004

Beck, K., Beedle, M., Van Bennekum, A., et al. (2001). Manifesto for agile software development. Available at: http://agilemanifesto.org/

Biffl, S., Aurum, A., Boehm, B., Erdogmus, H., Grünbacher, P., Fruhling, A. L. and Vreede, G.-J. (2006). ValueBased Software Engineering. Berlin: Springer. https://doi.org/10.1007/3-540-29263-2

Boehm, B. W. (2006). Value-based software engineering: overview and agenda. Value-Based Software Engineering, Springer Berlin Heidelberg, Berlin, Heidelberg, pp. 3-14. https://doi.org/10.1007/3-540-29263-2_1

Cagan, M. (2018). INSPIRED: How to Create Tech Products Customers Love, 2nd ed., John Wiley \& Sons, Inc.

Cleland-Huang, J. (2015). Injecting value-thinking into prioritization decisions. IEEE Software, 32(2), 14-18. https:// doi.org/10.1109/MS.2015.44

Conboy, K. (2009). Agility from first principles: reconstructing the concept of agility in information systems development. Information Systems Research, 20(3), 329-354. https:/ / doi.org/10.1287/isre.1090.0236

Forrester. (2013), Continuous Delivery: A Maturity Assessment Model, Cambridge, EUA. Available at: http://info.thoughtworks.com/rs/thoughtworks2/images/continuous_delivery_a_maturity_assessment_mo delfinal.pdf

Fowler, F. J. (2013). Survey Research Methods (Applied Social Research Methods), 5th ed., SAGE Publications.

Gilb, T. (2017). Value Planning, 1st ed., Kolbotn, Norway.

Golfarelli, M., Rizzi, S. and Turricchia, E. (2013). Multi-sprint planning and smooth replanning: an optimization model. Journal of Systems and Software, 86(9), 2357-2370. https://doi.org/10.1016/j.jss.2013.04.028

Hoda, R., Noble, J. and Marshall, S. (2011). The impact of inadequate customer collaboration on self-organizing agile teams. Information and Software Technology, 53(5), 521-534. https://doi.org/10.1016/j.infsof.2010.10.009

Kasauli, R., Knauss, E., Nilsson, A. and Klug, S. (2017). Adding value every sprint: a case study on large-scale continuous requirements engineering. 3rd WS on Continuous Requirements Engineering, Essen, Germany.

Khalifa, A. (2004). Customer value: a review of recent literature and an integrative configuration. Management Decision. https://doi.org/10.1108/00251740410538497

Khurum, M., Gorschek, T. and Wilson, M. (2013). The software value map - an exhaustive collection of value aspects for the development of software intensive products", Journal of Software: Evolution and Process, Vol. 25 No. 7, pp. 711-741. https://doi.org/10.1002/smr.1560

Kim, C.-K., Lee, D.-H., Ko, I.-Y. and Baik, J. (2007), “A lightweight value-based software architecture evaluation. Eighth ACIS International Conference on Software Engineering, Artificial Intelligence, Networking, and Parallel/Distributed Computing (SNPD 2007), IEEE, pp. 646-649. https://doi.org/10.1109/SNPD.2007.507

Komssi, M., Kauppinen, M., Töhönen, H., Lehtola, L. and Davis, A. M. (2015). Roadmapping problems in practice: value creation from the perspective of the customers. Requirements Engineering, $20(1), 45-69$. https://doi.org/10.1007/s00766-013-0186-3

Linaker, J., Sulaman, S. M., Host, M. and de Mello, R. M. (2015). Guidelines for Conducting Surveys in Software Engineering. Available at: http://portal.research.lu.se/portal/files/6062997/5463412.pdf

Maruping, L. M., Venkatesh, V. and Agarwal, R. (2009). A control theory perspective on agile methodology use and changing user requirements. Information Systems Research, $20(3)$, 377-399. https://doi.org/10.1287/isre.1090.0238

Mohammed, I. R., Shankar, R. and Banwet, D. K. (2008). Creating flex-lean-agile value chain by outsourcing. Business Process Management Journal, 14(3), 338-389. https:/ / doi.org/10.1108/14637150810876670

Murtazaev, A., Kang, S., Baik, J. and Lee, J. (2010). An Approach to Defining a Value-Based Software Development Process. 2010 IEEE/ACIS 9th International Conference on Computer and Information Science, IEEE, pp. 690-695. https://doi.org/10.1109/ICIS.2010.79 
Pass, S. and Ronen, B. (2014). Reducing the software value gap. Communications of the ACM, 57(5), 80-87. https://doi.org/10.1145/2594413.2594422

Poppendieck, M. (2011). Principles of lean thinking. IT Management Select, pp. 1-7.

Racheva, Z., Daneva, M., Sikkel, K. and Buglione, L. (2010). Business value is not only dollars - results from case study research on agile software projects. Product-Focused Software Process Improvement, Springer, Limerick, Ireland, pp. 131-145. https://doi.org/10.1007/978-3-642-13792-1_12

Racheva, Z., Daneva, M., Sikkel, K., Herrmann, A. and Wieringa, R. (2010). Do we know enough about requirements prioritization in agile projects: insights from a case study. 201018 th IEEE International Requirements Engineering Conference, IEEE, pp. 147-156. https:// doi.org/10.1109/RE.2010.27

Ramzan, M., Anwar, S. and Shahid, A. A. (2009). Need to redefine 'value' and case for a new 'software valuation' technique: An analytical study. Proceedings of International Conference on Computer Engineering and Applications, IACSIT Press, Singapore, pp. 400-407.

Salleh, C. N., Yahya, Y., Alaa, M., Altemimi, H. and Mukhtar, M. (2010). Value co-creation: embedding the value elements in critical success factor for e-government system development. 2010 International Symposium on Information Technology, IEEE, pp. 1-5. https://doi.org/10.1145/1852786.1852816

Sambinelli, F. and Borges, M. A. F. (2019a). Survey on Strategies to Increase Customer Value in Brazilian Agile Software Development Companies. 2019 14th Iberian Conference on Information Systems and Technologies (CISTI), IEEE, pp. 1-7. https://doi.org/10.23919/CISTI.2019.8760653

Sambinelli, F. and Borges, M. A. F. (2019b). Strategies to increase customer value in agile software development. Communications in Computer and Information Science, Springer, Cham, pp. 63-79. https://doi.org/10.1007/978-3030-14310-7_5

Santos, M. de A., Bermejo, P. H. de S., Oliveira, M. S. de and Tonelli, A. O. (2011). Agile practices: an assessment of perception of value of professionals on the quality criteria in performance of projects. Journal of Software Engineering and Applications, 4(12), 700-709. https:/ / doi.org/10.4236/jsea.2011.412082

Yin, R. K. (2017). Case Study Research: Design and Methods, 6th ed., London, England: SAGE Publications. 